\title{
Entomoponics: combining insect rearing and greenhouse vegetable production - a case study with Tenebrio molitor and high-wire cucumber cultivation
}

\author{
C.L. Coudron* iD, D. Deruytter, S. Craeye and P. Bleyaert \\ Inagro, Ieperseweg 87, 8800 Rumbeke-Beitem, Belgium; carl.coudron@inagro.be
}

Received: 20 July 2021 / Accepted: 27 August 2021

(C) 2021 Wageningen Academic Publishers

OPEN ACCESS (C) (i) RESEARCH ARTICLE

\begin{abstract}
Insect production is generally a monoculture where insects are kept in an enclosed environment with a stable climate to maximise production. To maintain these conditions air treatment is necessary, which results in high operational costs. Combining insect rearing with hydroponic greenhouse cultivation (HGC) of fruit vegetables might offer an opportunity for cost reduction. Fruit vegetables generally require more elevated air temperature, while leaving enough space under the substrate supporting gutters to allow insect rearing. In this study the feasibility of combining both production systems was evaluated with mealworms (Tenebrio molitor) and cucumber HGC serving as model species. The influence of the greenhouse climate was assessed by rearing mealworms simultaneous at two locations (a climate room and a cucumber HGC). Furthermore, pruning waste and aesthetically declined fruits could serve as a feed for insects. This was tested by comparing 4 different wet feeds (whole and mashed cucumber pruning, tomatoes and agar-agar). Larval growth was monitored and at harvest the mealworm yield was compared among treatments. Mealworm growth in the greenhouse was on average $8.1 \%$ slower than growth in a climate room even though the average ambient temperature in the greenhouse was lower and more variable $\left(22.1 \pm 3.30{ }^{\circ} \mathrm{C}\right.$ standard deviation compared to $27.0 \pm 0.34{ }^{\circ} \mathrm{C}$ ). Moreover, the results showed that the tested HGC residues can be used as wet feed given that mashed cucumber pruning gave similar results as agar-agar (control) and tomatoes even outperformed the control significantly in terms of growth. 'Entomoponics' is introduced as the name for the combination of insect production and HGC of vegetables as a way to create added value in unused heated space inside a greenhouse and valorise greenhouse residues.
\end{abstract}

Keywords: mealworm, hydroponics, insect production, waste valorisation

\section{Introduction}

Insect production systems are generally monocultures where the insects are kept in an enclosed environment (e.g. hangars, stables) in order to keep temperature optimal and prevent an infestation with insect pests (Dossey et al., 2016; Van Huis and Tomberlin, 2016). Rearing insects in greenhouses is not new, as black soldier flies (Hermetia illucens) are often reproduced in greenhouses (Sheppard et al., 2002). However, combining insect production, with crop production has to the authors' knowledge not yet been described despite the fact that there are several opportunities.
Hydroponic production of fruit vegetables like tomatoes, bell pepper and cucumber in greenhouses totals at 650 ha in Flanders and has been steadily increasing at an average rate of $2.5 \%$ per annuum in the last decade (Statbel, n.d.). Modern greenhouses increasingly break with all earthly connections and suspend their crops above the greenhouse floor, by using elevated gutters on which the substrate lies (Peet and Welles, 2005). For ergonomic reasons, gutters are suspended at a height of $60-80 \mathrm{~cm}$ above the soil surface. Moreover, greenhouse climate is of major importance for crop development, productivity and integrated pest management (Shipp et al., 2011). As a consequence, several measures are taken to control it. A minimum temperature is set below which heating starts and in order to keep the greenhouse temperature below a certain threshold, the 
greenhouse is ventilated and screens are deployed when solar irradiation is too strong. As a consequence, below the gutters there is plenty of unused climatised space available where insects could be reared.

Insects thrive in warmer conditions. Tenebrio molitor has a reported optimum temperature of $31{ }^{\circ} \mathrm{C}$ (Bjorge et al., 2018), H. illucens of $27-30{ }^{\circ} \mathrm{C}$ (Tomberlin et al., 2009) and Acheta domesticus of $30-35^{\circ} \mathrm{C}$ (Clifford and Woodring, 1990), being maintained continuously. However, greenhouse temperature tends to follow a diurnal and seasonal pattern, despite the aforementioned measures. In cucumber the minimum night temperature should be at least $18{ }^{\circ} \mathrm{C}$, with some papers recommending $22^{\circ} \mathrm{C}$, while temperature during the day is preferred to be around $28{ }^{\circ} \mathrm{C}$ (Singh et al., 2017). As for tomatoes, values between 18.3 and $32.2^{\circ} \mathrm{C}$ are considered to be optimal air temperatures during the entire growing season (Shamshiri et al., 2018). These temperatures, especially the daytime temperatures, are near the reported optimum of the mentioned insect species. However, the influence of the temperature variation on insect development is still unclear.

Finally, fruit vegetable cultivation systems, being mostly high-wire systems, produce plant waste on a regular basis. Old leaves are pruned throughout plant growth to maintain an optimal leaf area index (Pettersen et al., 2010). Excess fruits and aesthetically declined fruits are pruned as well to optimise yield and ensure quality of the fruits. This pruning waste is another opportunity for combining insect and vegetable production, as it could be used as a feed for insects.

In this study, T. molitor is used as a model species to assess the possibilities of co-producing insects and vegetables. Mealworms grow within the temperature ranges encountered in fruit vegetable greenhouses. The pruning waste can be used as a wet feed. They can be reared in lower crates, which allows for stacking multiple crates and increase productivity, without hampering crop care activities. Finally, as they do not fly or jump, they are less likely to escape.

Mealworms are capable of atmospheric water absorption when relative humidity $(\mathrm{RH})$ is above $88 \%$. (Hansen et al., 2004; Machin, 1975). However, other invertebrates such as flower mites (Acarus siro) thrive in these humid conditions (Hubert et al., 2013). In order to keep flower mite proliferation low in a mealworm production environment, $\mathrm{RH}$ is therefore generally set below $80 \%$. To compensate for this, free-choice water can be given to mealworms to improve growth and development (Urs and Hopkins, 1973). Most research is performed with mealworms grown on a dry feed (often wheat bran) supplied with fresh plant material as a source of water. Carrots are a popular choice in laboratories and among producers (Houbraken et al., 2016; Liu et al., 2020; Osimani et al., 2018; Rosiński et al.,
1979; Thévenot et al., 2018). However research by Liu et al. (2020) already proved other fresh plant materials such as cabbage or oranges to be equally effective. Solanaceae species such as tomato, bell pepper and aubergine should be handled with care as they produce glycoalkaloids, a group of metabolites with insecticidal properties which have been shown to affect mealworms (Marciniak et al., 2019; Spochacz et al., 2018). These glycoalkaloids are abundant in tomato leaves and unripe tomatoes, but are mostly absent in ripe tomatoes (Friedman and Levin, 1995). Aesthetically declined ripe tomatoes (and bell peppers), and cucumber foliage (and fruits) could therefore be suitable wet feeds for mealworm production.

The aim of this study was to assess the feasibility of combining mealworm rearing and cucumber production by: (1) rearing mealworms in a high-wire cucumber greenhouse; and (2) feeding these mealworms with greenhouse plant residues. The influence of a greenhouse climate on mealworm production was assessed by comparing growth and yield on 2 locations, in a high-wire cucumber greenhouse and in a room with a constant optimal temperature and humidity control. At each location 2 different vegetable residues were tested: aesthetically declined, ripe tomatoes and fresh cucumber foliage. The cucumber foliage was tested in the form of whole leaves, and cut in small pieces in an attempt to minimise fibrous leftovers, which might hamper separation of mealworms and the residue at harvest.

By exploring the possible synergies of these two production systems, this study might grant a basis that may promote future collaborations between horticulturists and insect producers and lead to a production system, for which we want to introduce the name 'entomoponics', analogous to the name 'aquaponics', for the combination of aquaculture and hydroponics.

\section{Material and methods}

\section{Mealworm colony}

The mealworm colony used in this study has been bred at the Inagro Insect Research Centre since 2013. They are kept in 60 by $40 \mathrm{~cm}$ plastic crates (inner surface area of $2,000 \mathrm{~cm}^{2}$ ) at a temperature of $27 \pm 0.3{ }^{\circ} \mathrm{C}, 60 \pm 2.5 \%$ relative humidity and in the dark except during feeding. The animals are fed ad libitum with INSECTUS Mealworm Grow (Mijten nv, Bekkevoort, Belgium) and chopped chicory roots. The $\mathrm{CO}_{2}$ concentration is monitored, and kept below $1,500 \mathrm{mg} / \mathrm{kg}$ by ventilation.

\section{Greenhouse information}

Cucumber plants (cv. Garpo by 'De Ruiter vegetable seeds') were planted in the greenhouse on 08/07/2020 (sowing date $10 / 06 / 2020$ ) at a stem density of 2.88 stems $/ \mathrm{m}^{2}$. Stem density 
was reduced to 2.4 and 1.92 by pruning $1 / 6$ on respectively 27/07/2020 and 11/08/2020. The cucumbers were planted in Grodan GT Master stonewool substrate slabs. Crop protection measures against aphids (Insecta: Hemiptera), thrips (Insecta: Thysanoptera), mites (Arachnida) and whiteflies (Insecta: Hemiptera) were the use of: predatory mites (Amblyseius swirskii and Neoseiulus californicus), a mixture of parasitic wasps (Aphidius colemani, Aphidius ervi, Aphelinus abdominalis, Praon volucre, Ephedrus cerasicola, Eretmocerus eremicus, Encarsia formosa), bioinsecticides (Bacillus thuringiensis ssp. aizawai, targeting Lepidoptera) and chemical insecticides (flonicamid and flupyradifurone). No specific measures were taken to shield the mealworms from insecticidal applications. The spraying itself was always carried out on the foliage. The zone below the lowest leaf was not sprayed and so the mealworms were not directly exposed. In addition, a horticultural fleece was used to cover the mealworm crates in the greenhouse throughout the trial. This was done in order to prevent birds from feasting on the mealworms, but this may also have reduced mealworm exposure to drift during insecticidal applications. Finally, some chemical fungicides were used as well. The greenhouse climate was controlled according to local practices with heating temperatures around $20^{\circ} \mathrm{C}$ during the days, $19{ }^{\circ} \mathrm{C}$ during the nights and ventilation temperature averaging around $22^{\circ} \mathrm{C}$.

\section{Experimental setup}

The trial took place during the summer of 2020. Mealworms were reared in 8 different treatments (2 locations and 4 different wet feeds). The 4 wet feed treatments were replicated 4 times at 2 locations, totalling at 32 crates. A stocking density of 18,000 mealworms per 60 by $40 \mathrm{~cm}$ crate was chosen, as this is expected to yield at least $2 \mathrm{~kg}$ of live mealworms per crate. However, as there were insufficient beetles to produce 576,000 mealworms during 1 oviposition run, the replicates were spread in time over 4 consecutive weeks.

Egg production was as follows, parental beetles (114 mg per beetle on average) were allowed to lay eggs for 6 days in 8 crates $(60$ by $40 \mathrm{~cm})$ with $250 \mathrm{~g}$ of beetles each. To increase the number of offspring per crate, the beetles were kept on a mesh as described by Deruytter $\mathrm{et} \mathrm{al}$. (2019), but instead of whole wheat flour, INSECTUS Mealworm Grow was used as a substrate. Every week the beetles were transferred to a crate with fresh substrate. On average the egg-equivalent of 296,000 mealworms (when determined after 4 weeks) were produced during every 6 days of oviposition. After ending oviposition, the crates with egg-substrate mixtures were allocated to their experimental location (climate room or greenhouse). Mealworms in the climate room were reared at $27 \pm 0.3{ }^{\circ} \mathrm{C}$ and $60 \pm 2.5 \%$, indicated hereafter as 'Controlled climate.' Four weeks after starting oviposition, the mealworms were redistributed at their desired densities (approximately 18,000 mealworms per crate). The amount of mealworms was estimated by counting the mealworm number per gram substrate in a representative sample. A mealworm-substrate mixture with approx. 18,000 mealworms was transferred to each experimental crate. INSECTUS was added in each crate up to a combined total weight of 3,850 g. This should result in at least $2 \mathrm{~kg}$ of live mealworm harvest per crate, based on preliminary research showing $0.214 \mathrm{~g}$ of INSECTUS per mealworm to be a good trade-off between weight gain and a low feed conversion ratio.

The crate setup in the greenhouse is visualised in Figure 1. The crates were placed underneath the suspended gutters on which the cucumbers grow, in between the heating pipes running along each side of the gutter.

Four weeks after starting oviposition, wet feed was supplied 3 times per week. Four different wet feeds were used at both locations: (1) whole and (2) mashed cucumber leaves, (3) low quality tomatoes and (4) agar-agar. Agar-agar (25 g/l, Brouwland nv, Beverlo, Belgium) served as a control wet feed as suggested by Deruytter et al. (2021). The tomatoes were aesthetically rejected fruits (cv. Marinice and Marlice) donated by tomato grower Gabel BVBA (Roeselare, Belgium). The tomatoes were cut into wedges (1/8) before they were given to the mealworms. The cucumber leaves were the result of maintenance pruning and originated from Inagro vzw (Roeselare, Belgium). The whole cucumber leaves were torn into coarse pieces to make them fit in the crates, hereafter called 'Leaves'. Part of the leaves were mashed with a garden shredder (Caravaggi TPF 15; Jose Luyckx BVBA, Rollegem-Kapelle, Belgium), hereafter called 'Leaf mash'. Rations were corrected for equal amounts of moisture among treatments. Agar-agar (2.5\% dry matter (DM)) acted as control wet feed. Tomato wet feed portions (4.4\% DM) were $2 \%$ bigger than agar-agar, cucumber pruning portions (whole or mashed, 6.3\% DM) were $4 \%$ bigger than agar-agar. The rations were evaluated every week and increased if necessary. In total each crate received $3,070 \mathrm{~g}$ of moisture during the course of the experiment. Total fresh weight portions were $3,150 \mathrm{~g}$ for agar crates, tomato crates received a total of 3,213 g, whole and mashed cucumber pruning crates received $3,276 \mathrm{~g}$.

\section{Measurements}

Mealworm growth was monitored by determining the average weight at weeks $2,6,8$ and 10 after starting oviposition. The content of the crates was gently homogenised and a sample of the substrate was taken. All mealworms were isolated from the sample, counted and weighed (ME203T; Mettler Toledo N.V., Zaventem, Belgium). If less than 100 mealworms were present in the sample, a new sample was taken in order to get an accurate estimate of the individual weight. 


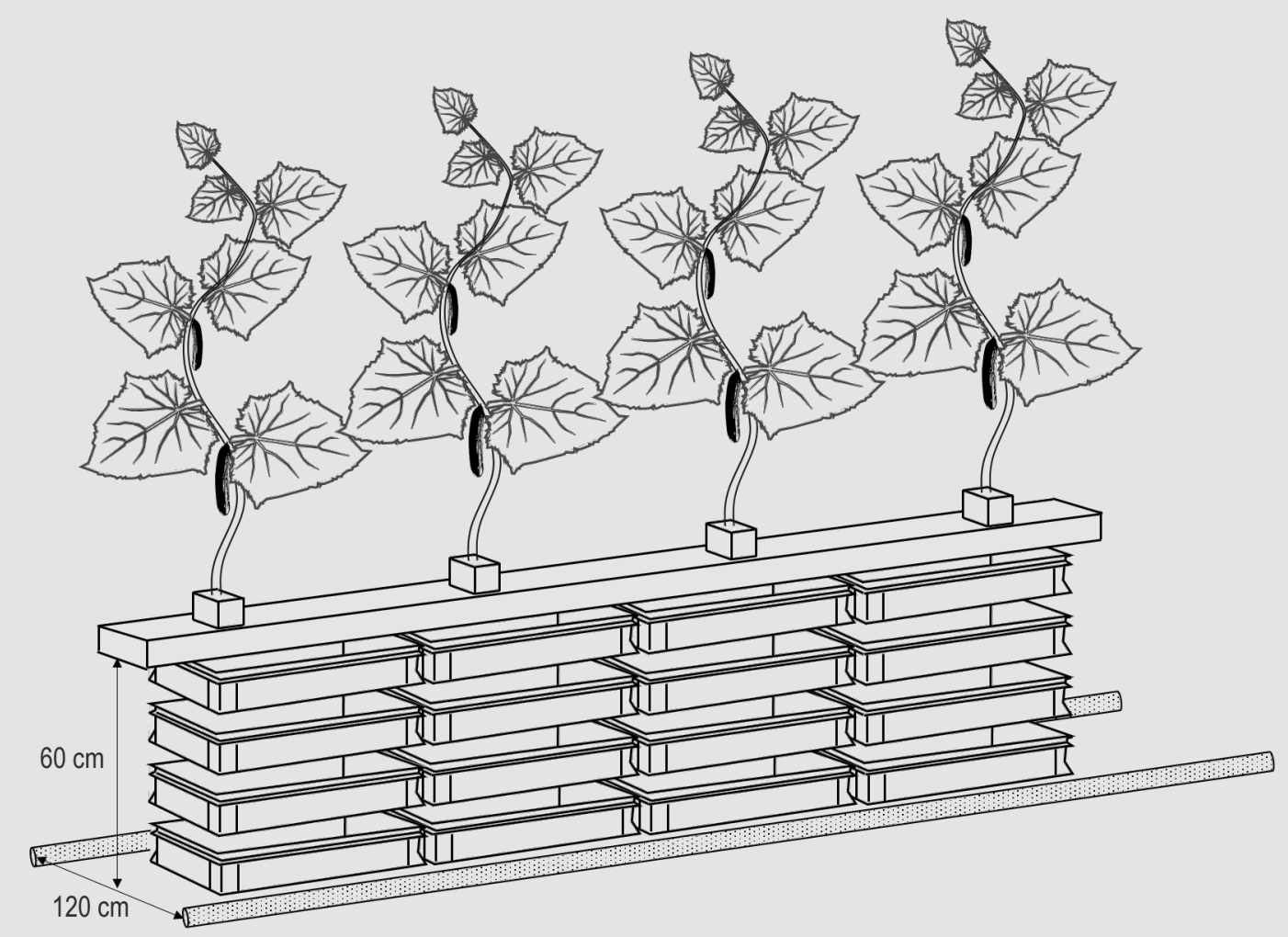

Figure 1. Schematic representation of the entomoponics setup in the greenhouse. The crates $(60 \times 40 \times 7.5 \mathrm{~cm})$ for mealworm growing are placed in between the heating pipes, beneath the hanging gutter of the high-wire cucumber cultivation system.

As maximum temperatures in greenhouses are influenced by outside weather conditions, there was a risk of overheating for crates at the greenhouse location during hot days. This could lead to high mortality and lower yields. It was therefore decided to monitor the temperature inside each crate using temperature sensors (LogTag TRIX-8). Every 30 minutes a value was recorded starting right after ending oviposition and their transfer to the greenhouse. Temperature difference $(\Delta \mathrm{T})$ was calculated between the inner crate temperature and the ambient temperature. Due to technical issues no data is present about inner crate temperatures under controlled climate.

Eleven weeks after starting oviposition each crate was harvested. At that time, the dry feed was depleted and pupae developed in most crates. Several harvest-parameters were determined. The crates were sieved ( $2 \mathrm{~mm}$ mesh), but because not all residues could be separated this way, further cleaning steps were necessary. All reported yields per crate are 'purified yields', obtained after additional cleaning. A 'purity ratio' was calculated as purified yield (fresh weight) divided by weight after sieving. The closer this number is to 1 , the better. From each purified mealworm batch a random sample of at least 100 mealworms was taken, they were counted and weighed to determine the mean individual mealworm weight. Based on this average weight, the number of mealworms in each crate was estimated. The residues were determined as the weight difference between the total content of each crate and the purified mealworm yield. Finally the feed conversion ratio (FCR) was calculated as the total amount of dry feed (INSECTUS and cumulative dry matter of all wet feed portions) that was given during the experiment divided by the total purified mealworm harvest (fresh weight). Dry matter was determined by drying the material at $60^{\circ} \mathrm{C}$ for 3 days.

\section{Statistical analysis}

The statistical analysis was performed using $R$ statistical software (R Core Team, 2020). A linear mixed effect model was used (Lme4 package) to assess the influence of time (continuous), wet feed (categorical with 4 levels) and location (categorical with 2 levels) on the growth of mealworm larvae. The mixed effect modelling was necessary due to the longitudinal nature of the data. Mealworm growth was expressed as a cubic equation of time. The average weights at harvest (week 11) were omitted for the estimation of the growth curves as dry feed became depleted (as intended) during their last week of growth before harvest. Thus, growth in faster growing crates was inhibited during the last week and slower growing crates could catch up during this week. The analysis started using the full model (Model 1). To determine the optimal model, the full model (Model 1) was reduced via backward selection 
until all parameters in the model were significant $(P<0.05)$ (Model 2).

$\log 10(M W)=T+T^{2}+T^{3}+\mathrm{L}+\mathrm{WF}+\mathrm{T} \times \mathrm{WF}+\mathrm{T} \times \mathrm{L}$

(Model 1)

$\log 10(\mathrm{MW})=\mathrm{T}+\mathrm{T}^{2}+\mathrm{T}^{3}+\mathrm{L}+\mathrm{WF}+\mathrm{T} \times \mathrm{WF} \quad($ Model 2$)$

With $\mathrm{MW}=$ 'mean mealworm weight' (mg), $\mathrm{T}=$ time (weeks), $\mathrm{L}=$ location (controlled climate or greenhouse) and $\mathrm{WF}$ = wet feed (agar, leaf mash, leaves and tomato).

Finally, to evaluate the harvest-parameters a 2-way ANOVA with post-hoc Tukey test was applied or when ANOVA assumptions were violated, a Wilcoxon rank-sum test was performed.

\section{Results}

\section{Climate conditions}

The distribution of the measured temperature conditions in the greenhouse (ambient and inner crate) and under controlled climate is shown in Figure 2. The measured ambient temperature in the greenhouse during the experiment was on average $22.3^{\circ} \mathrm{C}( \pm 3.3)$, the lowest recorded temperature being $14.7^{\circ} \mathrm{C}$; the highest $35.8^{\circ} \mathrm{C}$. In the crates, the average temperature was $26.8^{\circ} \mathrm{C}( \pm 2.9$, with a minimum value of $20.5{ }^{\circ} \mathrm{C}$ and a maximum of $37.5{ }^{\circ} \mathrm{C}$ ). Relative humidity in the greenhouse was on average $74.5 \%$ $( \pm 9.0 \%)$. Condition in the climate room were as follows: a temperature of $27 \pm 0.3{ }^{\circ} \mathrm{C}$ and $60 \pm 2.5 \%$ relative humidity.

\section{Comparison of mealworm growth}

Coefficient estimates of Model 2 are shown in Table 1 and predicted vs observed of Model 2 are shown in Figure 3. 'Location-Greenhouse' had a significant (negative) effect on mealworm growth. However, there was no significant interaction between location and time (Week), indicating that the difference in growth between the two locations remained quite constant, on average an $8.1 \%$ difference, and did not amplify further over time. Between wet feed and time a significant interaction effect was observed, but only for Tomato as indicated by the significant positive interaction term in Table 1.With every consecutive week the difference with the other feeds increased with $3.7 \%$. The other wet feeds did not significantly differ compared to the control wet feed agar.

The growth curves as predicted with 'Model 2' for the different wet feeds under controlled climate are shown in Figure 4. Ten weeks after starting oviposition, the mealworms reached an average weight of $73.5 \mathrm{mg}$ in the greenhouse and $80 \mathrm{mg}$ in the controlled climate. Mealworms fed with tomato ended up at $104 \mathrm{mg} 10$ weeks after starting oviposition, compared to $78.7 \mathrm{mg}$ on average for the other 3 feeds.

\section{Temperature development}

The evolution of the temperature difference $(\Delta \mathrm{T})$ between the inner crate and the ambient temperature of the greenhouse is shown in Figure 5 as well as the average daily growth rate of a greenhouse grown mealworm. During

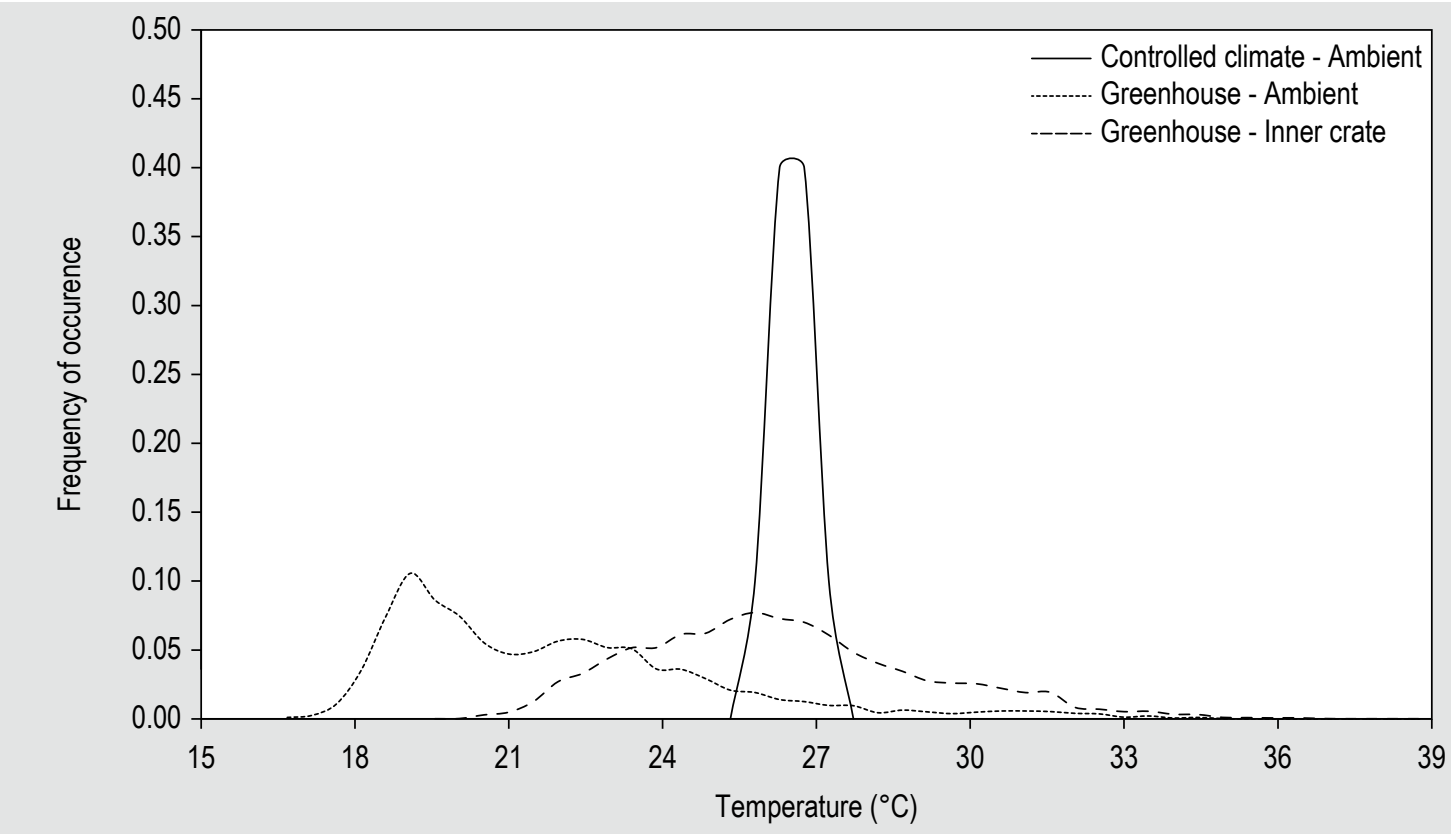

Figure 2. Distribution of the recorded ambient and inner crate temperature in the greenhouse as well as the distribution of the ambient temperature in the 'controlled climate'. 
Table 1. Estimated coefficients for Model 2 with 1 numerical variable (Time [weeks]) and 2 categorical variables (Location and Wet feed), and Location - Controlled climate and Wet feed - Agar as reference level. ${ }^{1}$

\begin{tabular}{|c|c|c|c|}
\hline & $\begin{array}{l}\text { Coefficient } \\
\text { estimate }\end{array}$ & $\begin{array}{l}\text { Standard } \\
\text { error }\end{array}$ & $P$-value ${ }^{2}$ \\
\hline Intercept & -0.36 & 0.029 & $<0.001$ \\
\hline Time $^{3}$ & -0.0027 & 0.00038 & $<0.001$ \\
\hline Time $^{2}$ & 0.043 & 0.0046 & $<0.001$ \\
\hline Time & 0.12 & 0.015 & $<0.001$ \\
\hline Location - Greenhouse & -0.037 & 0.010 & 0.0005 \\
\hline Wet feed - Leaf mash & 0.0011 & 0.025 & NS \\
\hline Wet feed - Leaves & 0.0084 & 0.025 & NS \\
\hline Wet feed - Tomato & -0.011 & 0.025 & NS \\
\hline Week $\times$ Wet feed - Leaf mash $^{b}$ & 0.0012 & 0.0052 & NS \\
\hline Week $\times$ Wet feed - Leaves $^{b}$ & -0.0052 & 0.0052 & NS \\
\hline Week $\times$ Wet feed - Tomato $^{a}$ & 0.016 & 0.0052 & $<0.006$ \\
\hline
\end{tabular}

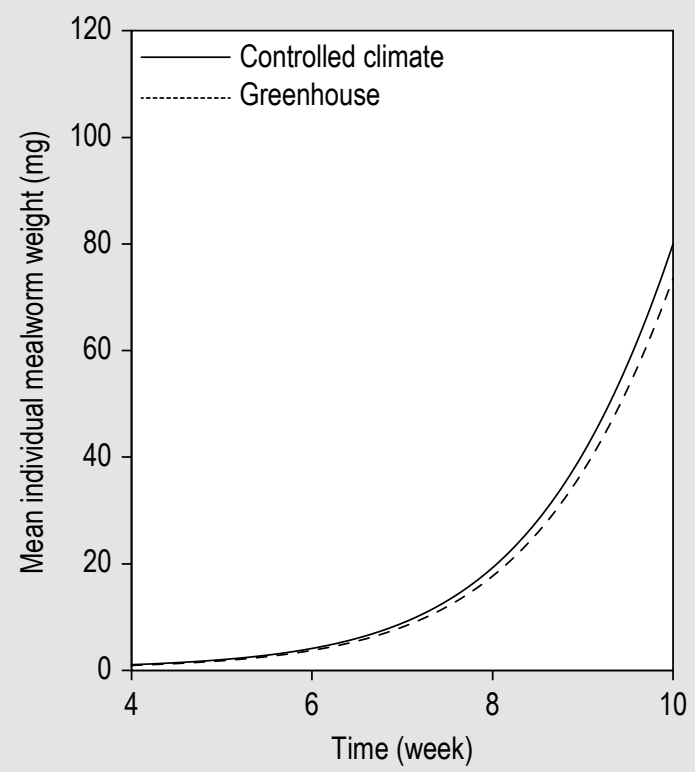

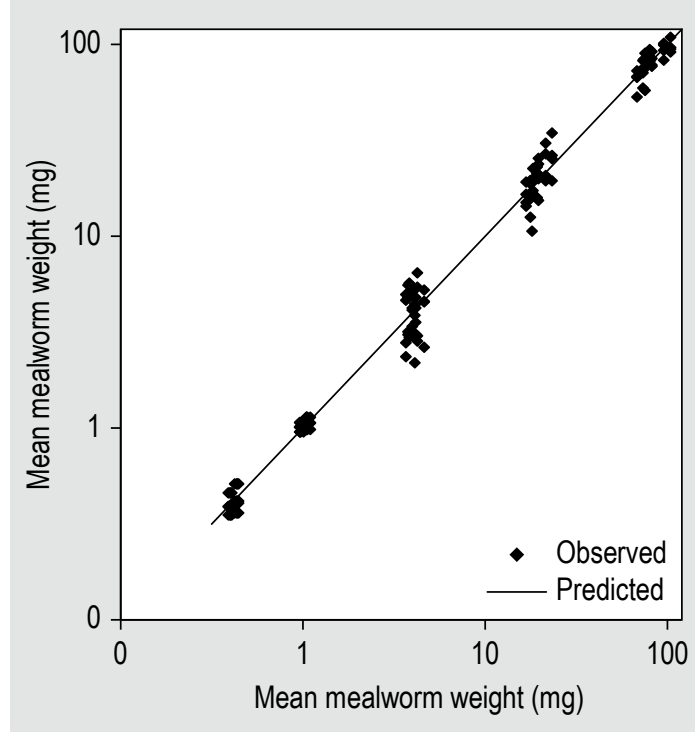

Figure 3. Predicted vs observed values of 'Model 2'.

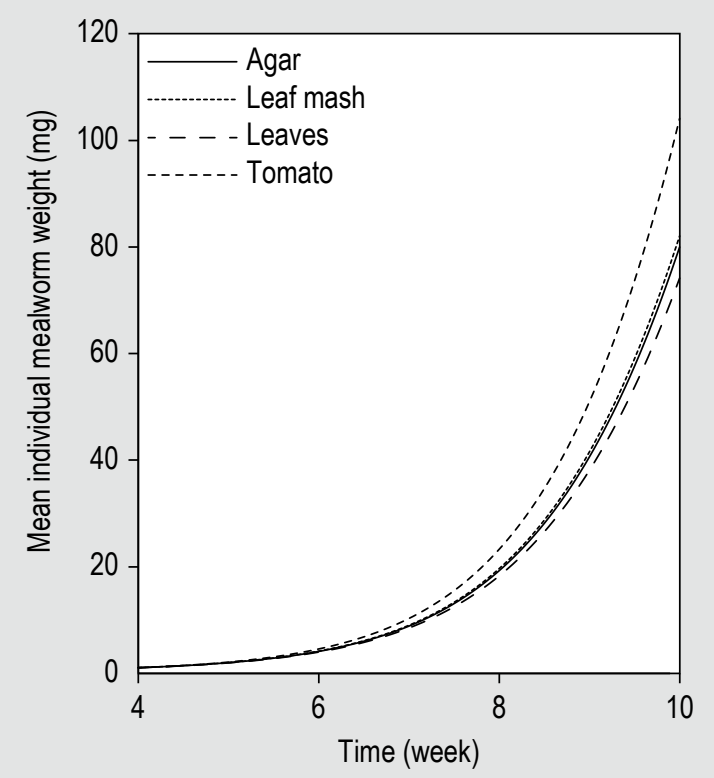

Figure 4. Predicted growth curves as described by 'Model 2 ' for both levels of 'Location' with agar as wet feed (left) and for the 4 levels of 'Wet feed' under controlled climate (right).

the first few weeks, the inside of the crates was at least $2{ }^{\circ} \mathrm{C}$ warmer than their environment, possibly as they were positioned closer to the heating pipes than the thermometer used to monitor the ambient greenhouse climate. However, the temperature difference increases during the course of the experiment and peaks at around $9.8^{\circ} \mathrm{C}$ at day 70 . The daily growth rate shows a similar trend as $\Delta \mathrm{T}$, indicating a correlation between both parameters.

\section{Parameters at harvest}

Several significant differences between the treatments were found among the parameters assessed at harvest. The results are summarised in Table 2 . The location where the larvae were reared resulted in significant differences in the parameters at harvest. On average the crates in the greenhouse yielded $161 \mathrm{~g}(8.0 \%)$ live mealworms per 


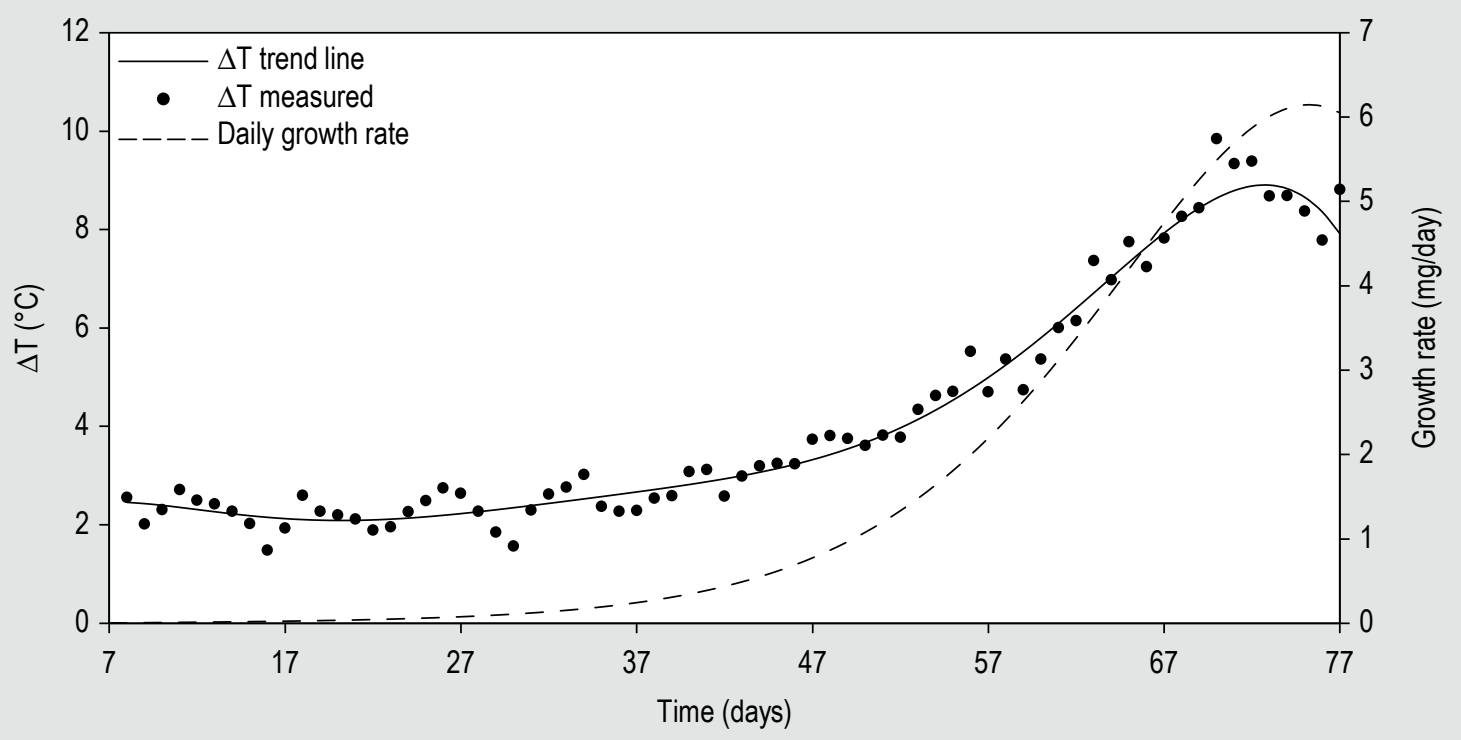

Figure 5. Average daily temperature difference between the environment and the inner crate (dots). Each dot is based on $\mathbf{7 2 0}$ measurements (48 measurements every day in 15 crates), starting right after ending oviposition and transfer to the greenhouse. The full line is the general trend line calculated with the method of least squares. The dashed line is the derivative of the estimated growth curve for mealworms in the greenhouse resulting in a daily growth rate.

crate less then these under a controlled climate. This lower yield resulted in a higher FCR $2.06 \mathrm{~kg}$ of dry feed per $\mathrm{kg}$ of live mealworms (compared to 1.86) and more residue per $\mathrm{kg}$ mealworms, leading to a lower purity of the mealworms after initial sieving. Despite the lower yield in the greenhouse, no significant differences were found between the number of mealworms per crate and their average weight.
The different wet feeds had a more profound impact on harvest-parameters than the location and no significant interactions between wet feed and location were found. Mealworms fed with tomatoes outperformed mealworms fed with leaves or leaf mash. Tomato fed mealworms were significantly larger and a higher yield per crate could be harvested. Mashed cucumber leaves did not perform significantly worse than the control wet feed agar for all

Table 2. The results of the two-way ANOVA with post-hoc Tukey test (or Wilcoxon rank-sum test when ANOVA assumptions were violated). The average values are displayed. The letters indicate significant differences $(P<0.05)$ within each categorical. When no letters are displayed, no significant differences were observed. The last row shows the $P$-value of a possible interaction effect.

\begin{tabular}{|c|c|c|c|c|c|c|}
\hline & $\begin{array}{l}\text { Individual } \\
\text { mealworm } \\
\text { weight }(\mathrm{mg})\end{array}$ & $\begin{array}{l}\text { Harvested } \\
\text { purified live yield } \\
\text { per crate (g) }\end{array}$ & $\begin{array}{l}\text { Number of } \\
\text { mealworms per } \\
1000\end{array}$ & $\begin{array}{l}\text { Feed conversion } \\
\text { ratio (dry feed } / \\
\text { live weight) }\end{array}$ & $\begin{array}{l}\text { Purity of product } \\
\text { after sieving (\%) }\end{array}$ & $\begin{array}{l}\text { Residue (residue } \\
\text { / live mealworm } \\
\text { weight) }\end{array}$ \\
\hline $\begin{array}{l}\text { Coefficient of variance [\%] } \\
\text { Wet feed }\end{array}$ & 12.9 & 8.8 & 15.5 & 13.9 & 1.6 & 17.9 \\
\hline Agar & $110^{a b}$ & $2,022^{a b}$ & 18.4 & $1.81^{b c}$ & $99.7^{\mathrm{a}}$ & $1.03^{b c}$ \\
\hline Leaf mash & $104^{b}$ & $1,848^{b c}$ & 18.0 & $2.06^{a b}$ & $98.5^{b}$ & $1.28^{\mathrm{ab}}$ \\
\hline Leaves & $99^{b}$ & $1,715^{\mathrm{C}}$ & 17.4 & $2.22^{\mathrm{a}}$ & $96.0^{c}$ & $1.44^{\mathrm{a}}$ \\
\hline Tomato & $127^{a}$ & $2,216^{a}$ & 17.8 & $1.69^{\mathrm{c}}$ & $99.7^{a}$ & $0.90^{c}$ \\
\hline \multicolumn{7}{|l|}{ Location } \\
\hline Controlled climate & 110 & $2,014^{a}$ & 18.6 & $1.86^{b}$ & $99.1^{\mathrm{a}}$ & $1.05^{b}$ \\
\hline Greenhouse & 109 & $1,853^{b}$ & 17.1 & $2.06^{a}$ & $97.7^{\mathrm{b}}$ & $1.31^{\mathrm{a}}$ \\
\hline Wet feed $\times$ Location $P$-value & 0.72 & 0.69 & 0.94 & 0.61 & 0.48 & 0.52 \\
\hline
\end{tabular}


but one parameter, purity after sieving. Coarse particles of similar size as the mealworms could not be separated during the first harvesting step and an adapted harvesting process with further refining methods was necessary. Mashing the leaves did improve the purity of the product after sieving compared to whole leaves. However, this was the only harvest-parameter affected by pre-treatment of the leaves. Whole leaves did perform the worst overall, yielding the smallest mealworms, lowest harvest per crate, the highest FCR, the highest residual mass and the lowest purity of the mealworms.

Figure 6 visualises the harvested purified yield for each crate. The yield of mealworms fed with whole leaves stands out for being the only object differing substantially ( $249 \mathrm{~g}$ ) between the 2 different locations. This specific treatment has major consequences for the overall performance of mealworms in the greenhouse as without it, the two locations do not differ significantly.

\section{Discussion}

The importance of proper rearing conditions for mealworm growth has been thoroughly described. Bjorge et al. (2018) showed the importance of temperature and found an optimal temperature at $31^{\circ} \mathrm{C}$. Below $15^{\circ} \mathrm{C}$ and above $39^{\circ} \mathrm{C}$ growth rate was close to zero. In our experiment, recorded ambient and inner crate temperatures remained well within this range. Despite the lower average and more variable ambient temperature in the greenhouse $\left(22.1 \pm 3.3{ }^{\circ} \mathrm{C}\right.$ compared to $27 \pm 0.34{ }^{\circ} \mathrm{C}$ ), the mealworms only developed 8.1\% slower than larvae reared under tightly controlled climate conditions. The microclimate of the crates was around $2{ }^{\circ} \mathrm{C}$ warmer as they were positioned closer to the heating pipes. Due to inner crate dynamics, additional heat production in the crates raised the temperature even further, eventually peaking at a temperature increase of $8.9^{\circ} \mathrm{C}$, resulting in a similar growth rate of the mealworms as for the control. The average long term inner crate temperature was close to the ambient temperature under controlled climate at $26.8{ }^{\circ} \mathrm{C}$, unfortunately no data is present about inner crate temperatures under controlled climate. The crates and substrate in which the mealworms live may have insulated them somewhat and might have protected them against short-term temperature extremes. Although most mealworm producers try to maintain a stable climate, this study indicates that, when the long term average temperature is optimal, fluctuations around this average (within certain boundaries) are acceptable. This phenomenon is well known for plant production in greenhouses, where it is applied in the practice of 'temperature integration' in order to reduce heating costs (Körner and Challa, 2003). Indeed, the possibility of lowering greenhouse temperature at low prevailing outside temperatures can contribute considerably in energy saving. A similar heating strategy could be used in mealworm production as $26 \%$ of total energy demand is required to keep the rearing facility at the desired temperature (Oonincx and De Boer, 2012). Mealworm growth in the greenhouse may have benefitted somewhat from a higher ambient relative humidity $(74.5 \%$ in the greenhouse compared to $60 \%$ under controlled climate) as a higher relative humidity is associated with faster growth (Johnsen et al., 2021).

The alternative wet feeds did influence mealworm growth and yield per crate even though portions were corrected for equal amounts of water. Tomatoes outperformed the control in terms of growth rate, however, yield per

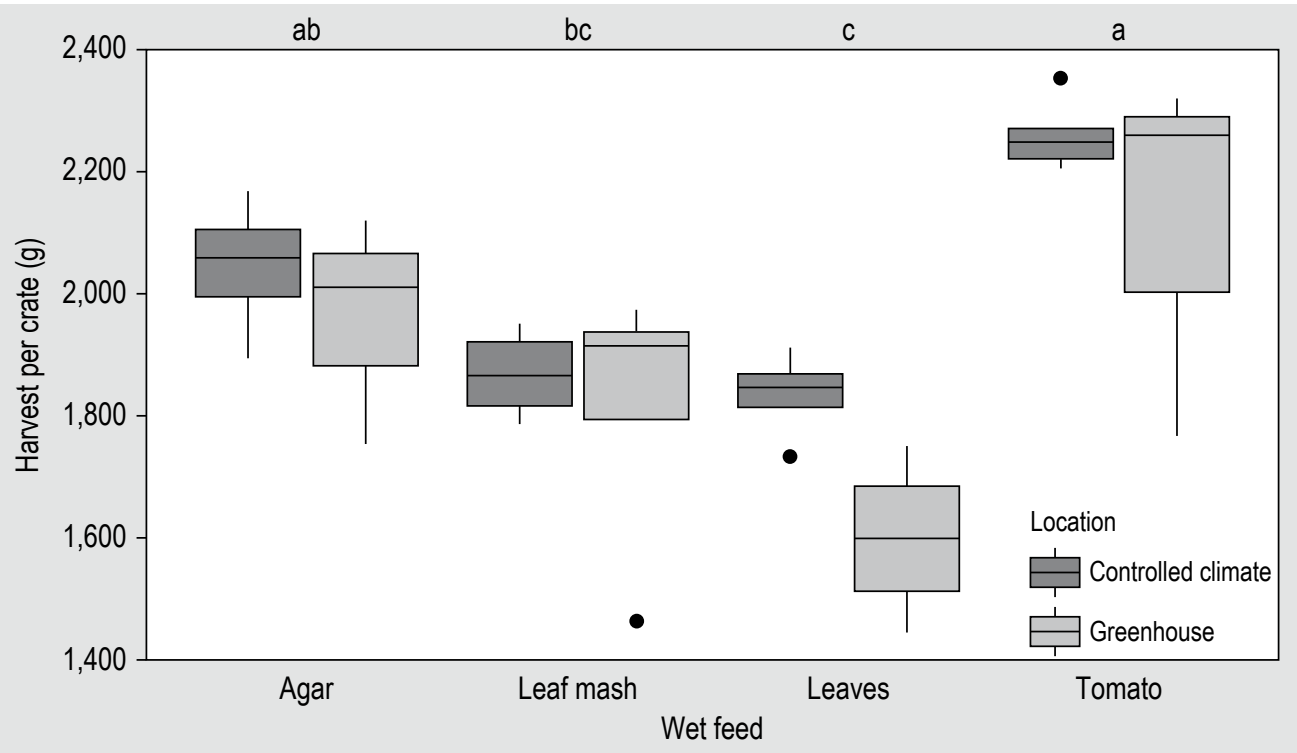

Figure 6. Boxplot representation of harvested purified live yield per crate $(g)$. The letters indicate significant differences between the different wet feeds $(P<0.05, n=4$ per boxplot). 
crate did not differ significantly. As it was decided to feed equal amounts of dry feed and harvest at a fixed moment rather than at a minimal weight, dry feed ran out sooner in tomato-fed-crates and the crates on other types of wet feed had time to catch up before harvest. On the other hand, whole cucumber leaves did yield $307 \mathrm{~g}$ mealworms per crate less compared to the control. Using foliage did also hamper harvest, as some remains of the unprocessed leaves could not be separated via ordinary sieving. This was partly resolved by mashing the leaves first, but adapted separation is required nonetheless. In total, around $1.6 \mathrm{~kg}$ of plant residues was processed per $\mathrm{kg}$ mealworms $(3.2$ $\mathrm{kg}$ of residues per mealworm crate with $2 \mathrm{~kg}$ mealworm yield). In the current setup there is room to produce $3 \mathrm{~kg}$ live mealworms per meter crate layer, which would be able to process $4.8 \mathrm{~kg}$ of plant residues over a period of 10 weeks. Depending on the cultivation system there is between $0.625 \mathrm{~m}$ and $1.25 \mathrm{~m}$ gutter $/ \mathrm{m}^{2}$ in a greenhouse.

There are several opportunities for future research to better understand the synergies between both production systems. First of all, there are still some uncertainties left. For example, this study presents the results of a trial performed during the summer months. However, the influence of seasonal and annual temperature variability on the growth rate of mealworms grown in a greenhouse as well as the influence of different crops, as each crop has its own optimal temperature settings, is still unknown. Another point of attention is on how produced insects will further react to beneficial insects and insecticides used in integrated pest management to control plagues (Orr, 2009). This study observed no clear adverse effects of the parasitic wasps (A. colemani, A. ervi, A. abdominalis, $P$. volucre, E. cerasicola, E. eremicus and E. formosa) and predatory mites (A. swirskii and $N$. californicus) or the insecticides (B. thuringiensis ssp. Aizawai, flonicamid and flupyradifurone) that were used as crop protection measures. B. thuringiensis ssp. Aizawai produces toxins with a high specificity against Lepidoptera and is not known to affect species of the Coleaptera order (Bravo et al., 2011). The effect of flonicamid on T. molitor has not been studied however, Cloyd and Dickinson (2006) and Garzón et al. (2015) found no adverse effect on two species of Coccinellidae (Coleoptera). As for flupyradifurone, again no studies describe the effect on T. molitor. However, Cloyd and Herrick (2018) and Colares et al. (2017) observed increased mortality in Dalotia coriaria (Coleoptera: Staphylinidae) and Hippodamia convergens (Coleoptera: Coccinellidae) respectively. In other words, some insecticides may pose real threats to reared insects, despite none were observed in this study. Even when measures are taken to prevent exposure during application, reared insects might still be exposed to the active components indirectly when they consume treated greenhouse residues. To continue, mealworm production in a greenhouse setting could be further optimised by testing different feeding substrates with different insulation properties that react differently to a variable climate. Some substrates may be better suited to protect the mealworms against the temperature extremes. Also, it could be assessed if mealworms produce $\mathrm{CO}_{2}$ at a rate where it could serve as a natural way of $\mathrm{CO}_{2}$ fertilisation for the crops above them. This could (partially) replace $\mathrm{CO}_{2}$ currently often originating from exhaust gasses (Lansink and Bezlepkin, 2003). Finally, this study focusses on mealworms, but the feasibility of producing other insect species (e.g. A. domesticus or Alphitobius diaperinus) in a greenhouse setting could be assessed.

In conclusion, our experiment gives a first indication that greenhouses where cucumbers are cultivated and potentially other hydroponic greenhouse cultivations with hanging gutters, such as tomatoes or bell peppers, could be suitable environments for mealworm production. Some of the plant-residues coming from these crops, such as aesthetically declined ripe tomatoes and cucumber foliage, are suitable wet feeds for mealworm production. Combining both vegetable and mealworm production in an entomoponics system can be of mutual benefit. For horticulturists it can serve as a way to process plant residues that would otherwise be discarded and to valorise unused heated space in the greenhouse. As for mealworm producers it can be a way to save energy that would be needed to climatise the rearing facility and to reduce the cost of wet feed that would otherwise need to be acquired.

\section{Acknowledgements}

The authors thank Lukas De Praetere and Anne Devos for their help in carrying out the experiment. This research was funded by Interreg NWE, grant number NWE1004, ValuSect - Valuable inSects; and co-funded by Vlaams Agentschap Innoveren \& Ondernemen and West Flanders province.

\section{Conflict of interest}

The authors declare no conflict of interest.

\section{References}

Bjorge, J.D., Overgaard, J., Malte, H., Gianotten, N. and Heckmann, L.H., 2018. Role of temperature on growth and metabolic rate in the tenebrionid beetles Alphitobius diaperinus and Tenebrio molitor. Journal of Insect Physiology 107: 89-96. https://doi.org/10.1016/j. jinsphys.2018.02.010

Bravo, A., Likitvivatanavong, S., Gill, S.S. and Soberón, M., 2011. Bacillus thuringiensis: a story of a successful bioinsecticide. Insect Biochemistry Molecular Biology 41: 423-431.

Clifford, C.W. and Woodring, J., 1990. Methods for rearing the house cricket, Acheta domesticus (L.), along with baseline values for feeding rates, growth rates, development times, and blood composition. Journal of Applied Entomology 109: 1-14. 
Cloyd, R.A. and Dickinson, A., 2006. Effect of insecticides on mealybug destroyer (Coleoptera: Coccinellidae) and parasitoid Leptomastix dactylopii (Hymenoptera: Encyrtidae), natural enemies of citrus mealybug (Homoptera: Pseudococcidae). Journal of Economic Entomology 99: 1596-1604.

Cloyd, R.A. and Herrick, N.J., 2018. Effects of pesticides on the survival of rove beetle (Coleoptera: Staphylinidae) and insidious flower bug (Hemiptera: Anthocoridae) adults. Journal of Economic Entomology 111: 78-88.

Colares, F., Michaud, J., Bain, C.L. and Torres, J.B., 2017. Relative toxicity of two aphicides to Hippodamia convergens (Coleoptera: Coccinellidae): implications for integrated management of sugarcane aphid, Melanaphis sacchari (Hemiptera: Aphididae). Journal of Economic Entomology 110: 52-58.

Deruytter, D., Coudron, C.L., Claeys, J. and Feed, 2021. The influence of wet feed distribution on the density, growth rate and growth variability of Tenebrio molitor. Journal of Insects as Food and Feed 7: 141-149.

Deruytter, D., Coudron, C.L. and Teerlinck, S., 2019. Influence of crate size, oviposition time, number of adults and cannibalism on the reproduction of Tenebrio molitor. Journal of Insects as Food and Feed 5: 247-255.

Dossey, A.T., Morales-Ramos, J.A. and Rojas, M.G., 2016. Insects as sustainable food ingredients: production, processing and food applications. Academic Press, Cambridge, MA, USA.

Friedman, M. and Levin, C.E., 1995. Alpha-tomatine content in tomato and tomato products determined by HPLC with pulsed amperometric detection. Journal of Agricultural Food Chemistry 43: 1507-1511.

Garzón, A., Medina, P., Amor, F., Viñuela, E. and Budia, F., 2015. Toxicity and sublethal effects of six insecticides to last instar larvae and adults of the biocontrol agents Chrysoperla carnea (Stephens) (Neuroptera: Chrysopidae) and Adalia bipunctata (L.) (Coleoptera: Coccinellidae). Chemosphere 132: 87-93.

Hansen, L.L., Ramløv, H. and Westh, P., 2004. Metabolic activity and water vapour absorption in the mealworm Tenebrio molitor L. (Coleoptera, Tenebrionidae): real-time measurements by twochannel microcalorimetry. Journal of Experimental Biology 207: 545-552.

Houbraken, M., Spranghers, T., De Clercq, P., Cooreman-Algoed, M., Couchement, T., De Clercq, G., Verbeke, S. and Spanoghe, P., 2016. Pesticide contamination of Tenebrio molitor (Coleoptera: Tenebrionidae) for human consumption. Food Chemistry 201: 264-269.

Hubert, J., Pekár, S., Aulický, R., Nesvorná, M. and Stejskal, V., 2013. The effect of stored barley cultivars, temperature and humidity on population increase of Acarus siro, Lepidoglyphus destructor and Tyrophagus putrescentiae. Experimental Applied Acarology 60: 241-252.

Johnsen, N., Andersen, J. and Offenberg, J., 2021. The effect of relative humidity on the survival and growth rate of the yellow mealworm larvae (Tenebrio molitor, Linnaeus 1758). Journal of Insects as Food and Feed 7(3): 311-318.
Körner, O. and Challa, H., 2003. Design for an improved temperature integration concept in greenhouse cultivation. Computers and Electronics in Agriculture 39: 39-59. https://doi.org/10.1016/s01681699(03)00006-1

Lansink, A.O. and Bezlepkin, I., 2003. The effect of heating technologies on $\mathrm{CO} 2$ and energy efficiency of Dutch greenhouse firms. Journal of environmental management 68: 73-82.

Liu, C., Masri, J., Perez, V., Maya, C. and Zhao, J., 2020. Growth performance and nutrient composition of mealworms (Tenebrio molitor) fed on fresh plant materials-supplemented diets. Foods 9: 151.

Machin, J., 1975. Water balance in Tenebrio molitor, L. Larvae; the effect of atmospheric water absorption. Journal of Comparative Physiology 101: 121-132.

Marciniak, P., Kolińska, A., Spochacz, M., Chowański, S., Adamski, Z., Scrano, L., Falabella, P., Bufo, S.A. and Rosiński, G., 2019. Differentiated effects of secondary metabolites from Solanaceae and Brassicaceae plant families on the heartbeat of Tenebrio molitor pupae. Toxins 11: 287.

Oonincx, D.G. and De Boer, I.J., 2012. Environmental impact of the production of mealworms as a protein source for humans - a life cycle assessment. PLoS ONE 7: e51145.

Orr, D., 2009. Biological control and integrated pest management, integrated pest management: innovation-development process. Springer, Cham, Switzerland, pp. 207-239.

Osimani, A., Milanović, V., Cardinali, F., Garofalo, C., Clementi, F., Ruschioni, S., Riolo, P., Isidoro, N., Loreto, N. and Galarini, R., 2018. Distribution of transferable antibiotic resistance genes in laboratory-reared edible mealworms (Tenebrio molitor L.). Frontiers in Microbiology 9: 2702.

Peet, M. and Welles, G., 2005. Greenhouse tomato production. Crop Production Science in Horticulture 13: 257.

Pettersen, R.I., Torre, S. and Gislerød, H.R., 2010. Effects of leaf aging and light duration on photosynthetic characteristics in a cucumber canopy. Scientia Horticulturae 125: 82-87.

$\mathrm{R}$ Core Team, 2020. A language and environment for statistical computing. R foundation for statistical computing, Vienna, Austria. Available at: http://www.R-project.org/.

Rosiński, G., Wrzeszcz, A. and Obuchowicz, L., 1979. Differences in trehalase activity in the intestine of fed and starved larvae of Tenebrio molitor L. Insect Biochemistry 9: 485-488.

Shamshiri, R.R., Jones, J.W., Thorp, K.R., Ahmad, D., Che Man, H. and Taheri, S., 2018. Review of optimum temperature, humidity, and vapour pressure deficit for microclimate evaluation and control in greenhouse cultivation of tomato: a review. International Agrophysics 32: 287-302.

Sheppard, D.C., Tomberlin, J.K., Joyce, J.A., Kiser, B.C. and Sumner, S.M., 2002. Rearing methods for the black soldier fly (Diptera: Stratiomyidae). Journal of Medical Entomology 39: 695-698.

Shipp, L., Johansen, N., Vänninen, I. and Jacobson, R., 2011. Greenhouse climate: an important consideration when developing pest management programs for greenhouse crops. Acta Horticulturae 893: 133-143. https://doi.org/10.17660/ActaHortic.2011.893.8 
Singh, M.C., Singh, J.P., Pandey, S.K., Mahay, D. and Shrivastva, V., 2017. Factors affecting the performance of greenhouse cucumber cultivation - a review. International Journal of Current Microbiology and Applied Sciences 6: 2304-2323. https://doi.org/10.20546/ ijcmas.2017.610.273

Spochacz, M., Chowański, S., Szymczak, M., Lelario, F., Bufo, S.A. and Adamski, Z., 2018. Sublethal effects of Solanum nigrum fruit extract and its pure glycoalkaloids on the physiology of Tenebrio molitor (mealworm). Toxins 10: 504.

Statbel, n.d. Land- en tuinbouwbedrijven. Statbel, Brussels, Belgium. Available at: https://statbel.fgov.be/nl/themas/landbouw-visserij/ land-en-tuinbouwbedrijven\#figures
Thévenot, A., Rivera, J.L., Wilfart, A., Maillard, F., Hassouna, M., Senga-Kiesse, T., Le Féon, S. and Aubin, J., 2018. Mealworm meal for animal feed: environmental assessment and sensitivity analysis to guide future prospects. Journal of Cleaner Production 170: 12601267.

Tomberlin, J.K., Adler, P.H. and Myers, H.M., 2009. Development of the black soldier fly (Diptera: Stratiomyidae) in relation to temperature. Environmental Entomology 38: 930-934.

Urs, K.C.D. and Hopkins, T.L., 1973. Effect of moisture on growth rate and development of two strains of Tenebrio molitor L. (Coleoptera Tenebrionidae). Journal of Stored Products Research 8: 291-297. https://doi.org/10.1016/0022-474X(73)90045-3

Van Huis, A. and Tomberlin, J.K., 2016. Insects as food and feed: from production to consumption. Wageningen Academic Publishers, Wageningen, the Netherlands. 
